\title{
Optimization of banana crop by-products solvent extraction for the production of bioactive compounds
}

\author{
Sara Díaz ${ }^{1}\left[\right.$ · Antonio N. Benítez ${ }^{1} \cdot$ Sara Ramírez-Bolaños $^{2} \cdot$ Lidia Robaina $^{2} \cdot$ Zaida Ortega $^{1}$
}

Received: 6 April 2021 / Revised: 18 June 2021 / Accepted: 26 June 2021

(c) The Author(s) 2021, corrected publication 2021

\begin{abstract}
The aim of this work is the optimization of phenolic compound extraction from three by-products of banana crops (rachis, discarded banana, and banana's pseudostem pulp), as a way to valorize them through a green extraction process. The influence of the temperature and aqueous ethanol concentration (Et-OH) on extract properties (total phenol content (TPC) and antioxidant activity) was firstly analyzed. $78{ }^{\circ} \mathrm{C}$ and ethanol concentrations close to $50 \%$ yielded the best results for the three materials. The equations obtained by the response surface methodology gave a satisfactory description of the experimental data, allowing optimizing the extraction conditions. Under optimized conditions, time influence was then assessed, although this parameter seemed not influence results. Among the three by-products, rachis extract $\left(60 \% \mathrm{Et}-\mathrm{OH}, 78{ }^{\circ} \mathrm{C}\right.$, and $\left.30 \mathrm{~min}\right)$ presented the highest TPC (796 mg gallic acid/100 g of dried material) and antioxidant activity (6.51 mg Trolox equivalents/g of dried material), followed by discarded banana, and pseudostem pulp. Under the optimal conditions, experiments were performed at a larger scale, allowing to determine the extraction yields (EY) and to characterize the extracts. The highest EY was obtained for the rachis (26\%), but the extract with the highest activity was obtained for discarded banana (50\% Et-OH, $78{ }^{\circ} \mathrm{C}$, and $60 \mathrm{~min}$ ), which presented a TPC of $27.26 \mathrm{mg} / \mathrm{g}$ extract corresponding to $54.59 \mathrm{mg}$ Trolox equivalents/g extract. This study contributes to the valorization of banana crops residues as a source of polyphenolic compounds with bioactive functions that can be extracted under economic extraction conditions.
\end{abstract}

Keywords Banana wastes $\cdot$ Biomass valorization $\cdot$ Antioxidant extraction $\cdot$ Response surface methodology $\cdot$ Polyphenolic compounds $\cdot$ DPPH activity

Sara Díaz

sara.diazguzman@ulpgc.es

Antonio N. Benítez

antonionizardo.benitez@ulpgc.es

Sara Ramírez-Bolaños

sara.ramirez@ulpgc.es

Lidia Robaina

lidia.robaina@ulpgc.es

Zaida Ortega

zaida.ortega@ulpgc.es

1 Departamento de Ingeniería de Procesos, Universidad de Las Palmas de Gran Canaria, Edificio de Fabricación Integrada, Parque Científico - Tecnológico de la ULPGC, Campus universitario de Tafira Baja, 35017 Las Palmas de Gran Canaria, Las Palmas, Spain

2 Grupo de Investigación en Acuicultura (GIA), IU-ECOAQUA, Universidad de Las Palmas de Gran Canaria, Crta. Taliarte s/n, 35214 Telde, Spain

\section{Introduction}

The agricultural production and the agro-food industry produce large volumes of residues and their utilization for the production of value-added products has received much attention in recent years. One example of it is the banana cultivation. Banana is cultivated over 130 countries and it is the second largest produced fruit, after citrus [1], with an estimated gross production exceeding 116 million tons [2]. Particularly, in the Canary Islands, 400, 000 tons of banana are produced each year [3], being the largest banana producer in the European Union.

Banana crops produce a great amount of wastes at the farming site (pseudostem, leaves, and inflorescences), because of the necessity of decapitation of the whole plant so that the young suckers can replace the mother plant, and at the processing sites (rachis and discarded bananas) where the fruit is packaged. Around four tons of wastes are generated for each ton of fruit harvested [4]. Such amount of 
agricultural residues requires of innovative ideas to turn these readily available resource into value-added products. This could help the waste management but also represent an interesting income for banana producers, boosting in this way the regional economy [5], particularly in the Canary Islands where banana crop is an essential pillar from the economic point of view. Previous studies have shown that different fractions of banana by-products present compounds with significant antibacterial and antioxidant properties as is the case of banana skins [6-10] and fruit pulp [11], rhizome $[12,13]$, inflorescence [14, 15], pseudostem [12, 16-20], and leafs [21]. On the other hand, it exists a worldwide trend to avoid or minimize the use of synthetic food additives [22] and the possible toxic effects during long-term intake of some synthetic antioxidants [23], reason why much interest has been paid during the last few years at naturally occurring antioxidants. Therefore, the extraction of polyphenols, most significant compounds for the antioxidant properties of plant raw materials [24] with a very high commercial value, could be an interesting alternative method to valorize the widely available amount of banana crop wastes.

The replacement of synthetic antioxidants by natural antioxidants requires promising, safe, efficient, and economical procedures for extraction of these compounds from plant materials, in order to ensure commercial sustainability [22]. The solvent extraction is a well-known technique and easily scalable to an industrial scale, comparing with other new non-conventional methods (such as ultrasound, microwave, and pressure-assisted extractions) that, although allow to reduce the energy and solvent requirement, still present some difficulties to be applied at an industrial level [25]. The recovery of polyphenols is influenced by the type and concentration of solvent and also by the extraction conditions (time, ratios of solvent volume to sample weight), as well as different physical parameters, such as application of pressure, temperature, and radiation time [22]. Although solvent extraction has been used with a wide variety of plant materials, as each product has unique properties in terms of structure and composition, the behavior of the resulting material-solvent system is unpredictable [13], and comparative studies are required for each substrate [7]. Regarding banana crops by-products, although, as commented, there are a considerable number of studies showing their important content in antioxidants, these studies are limited to perform the extraction under single conditions. Except from banana peels [7, 10, 26, 27], no attention is paid to the influence of the different extraction parameters such as type and percentage of solvent, temperature and extraction times, or to the sustainability of the process, aspects that are taken into consideration in the present study.

The main objective of this study is to optimize the extraction of natural antioxidants from three wastes coming from banana crops: rachis, discarded bananas, and banana's pseudostem pulp (a by-product obtained in the mechanical fiber extraction of the pseudostem [28]). These three by-products have been studied separately as they are very different in purpose in the plant, and thus in composition, and the optimization of compound extraction must be done individually. A solvent extraction was carried out using ethanol as extracting agent, as it has lower cost than others (e.g., methanol), is recognized as GRAS (generally recognized as safe) and suitable for food application and environmental safety, as well as it has the advantage of being recoverable by evaporation [29]. The optimization of the temperature and solvent concentration was carried out through the equations obtained by the response surface methodology (RSM). Then, the influence of the extraction time was also evaluated. Finally, the extraction yield at a larger scale and the characterization of the obtained extracts was carried out under the optimal conditions found for each material. To the best of our knowledge, this is the first study where the optimization of the antioxidant extraction from these three banana by-products using a safe, economical, and green extraction procedure is conducted.

\section{Materials and methods}

\subsection{Materials}

\subsubsection{Feedstocks}

Three different by-products coming from banana crop were used as the raw materials for the present study: banana's pseudostem pulp (BPP), rachis, and discarded green banana. For the obtention of BPP, pseudostems from Musa acuminata Dwarf Cavendish (Gran Enana cultivar) randomly collected from an agro-industrial plantation in Arguineguín were processed as described in [28]. In addition to the fiber, another by-product is generated in this process, banana's pseudostem pulp (BPP), one of the raw material for this study. On the other hand, the rachis and discarded green bananas, also from Musa acuminata Dwarf Cavendish, the other two feedstock of the present study, were supplied by Cooperativa Agrícola del Norte de Gran Canaria, where classification of bananas and packaging labors are done. The three different fractions were separately lyophilized at $-50{ }^{\circ} \mathrm{C}$ and 0.3 mbar and milled to particles smaller than $0.5 \mathrm{~mm}$ using an Ultra Centrifugal Mill ZM200 of Retsch. After milling, the fractions were homogenized and stored in plastic containers at $4{ }^{\circ} \mathrm{C}$, protected from light until use.

\subsubsection{Reagents}

Gallic acid and 6-hydroxy-2,5,7,8-tetramethylchroman-2-carboxylic acid (Trolox) were purchased from 
Sigma-Aldrich. 2,2-Diphenyl-1-picrylhydrazyl (DPPH free radical) was purchased from Thermo Fisher and Folin Ciocalteu reagent was purchased from VWR. Other reagents used during the experiments were all from analytical grade.

\subsection{Influence of operational conditions on antioxidant extraction}

The extractions were carried out using $1 \mathrm{~g}$ of sample with the solvent at a ratio of 1:20 (weight of sample/volume of solvent) in $50-\mathrm{mL}$ centrifugal tubes. The samples were placed in a thermostatic water bath with magnetical agitation and the time and temperature were controlled during the assays. After the extraction, samples were centrifuged at $3000 \mathrm{rpm}$ for $15 \mathrm{~min}$ and the supernatant was filtered for further analyses.

\subsubsection{Optimization of concentration of solvent and temperature}

Extraction time was fixed in $1 \mathrm{~h}$ and water-ethanol concentration (\%Et-OH) and temperature (T) were used as independent variables. The influence of these 2 factors was evaluated at 3 levels ( $3^{2}$ factorial experiment): temperature (room temperature, $50{ }^{\circ} \mathrm{C}$, and $78{ }^{\circ} \mathrm{C}$ ) and aqueous ethanol concentration $(20,40$, and $60 \%)$. The range of variation between the lower and upper limits of each independent variable was established in base to the literature and some preliminary tests. The experimental design conditions are shown in Table 2. All experiments were done in duplication for each by-product.

Total phenolic compounds (TPC) and antioxidant activity according to DPPH (2,2-diphenyl-1-picrylhydrazyl) assay were determined in the filtered extracts (according to Section 2.3) as response variables of the experimental design. Results are expressed as mean \pm standard deviation (SD) of duplicates. Two-way ANOVA was used to analyze the effect of \% Et-OH and T on the TPC and DPPH radical scavenging activity and the significance of the difference between means was determined by Tukey's test using R-Commander (R-Studio Software). For each response, the mean values obtained from the duplicates were fitted to a second-order polynomial model as follows:

$$
\begin{aligned}
& \mathrm{f}(\mathrm{T}, \% \mathrm{Et}-\mathrm{OH})=\mathrm{p} 00+\mathrm{p} 10 * \mathrm{~T}+\mathrm{p} 01 * \% \mathrm{Et}-\mathrm{OH} \\
& +\mathrm{p} 20 * \mathrm{~T}^{2}+\mathrm{p} 11 * \mathrm{~T} * \% \mathrm{Et}-\mathrm{OH}+\mathrm{p} 02 * \% \mathrm{Et}-\mathrm{OH}^{2}
\end{aligned}
$$

The response surfaces were plotted using Matlab and the fit of the models to the experimental data was given by the coefficient of determination $\left(\mathrm{R}^{2}\right)$.

The optimum conditions of the extraction were numerically determined using the equations obtained for the TPC and the antioxidant activity (DPPH inhibition) for each byproduct. Some tests were performed close to the predicted optimized conditions and both, predicted and observed values, were compared.

\subsubsection{Influence of the time on the antioxidant extraction}

Under optimal conditions (temperature and ethanol concentration) found for each feedstock, the influence of the extraction duration was also tested. Independent samples were subjected to different times of treatment between $15 \mathrm{~min}$ and $2 \mathrm{~h}$, following the previously described procedure, and TPC and DPPH inhibition were determined in the filtered extracts (according to Section 2.3).

\subsection{Determination of extraction yield}

Finally, under the operational conditions selected for each material (temperature, ethanol concentration, and time), experiments were carried out at a larger scale $(\times 5)$ in order to calculate the extraction yields and to characterize the obtained extracts. The assays were done in duplicate. In this occasion, an Erlenmeyer flask of $250 \mathrm{~mL}$ of capacity containing $5 \mathrm{~g}$ of sample and $100 \mathrm{~mL}$ of solvent were placed in a thermostatic water bath and magnetically stirred. To avoid solvent loss, a reflux system was connected to the extraction flask. The time and the temperature inside the reaction flask were controlled during the assays. The liquid extract and the remaining solid were separated by filtration. A sample of the liquid was analyzed to determine the TPC and the antioxidant activity according to DPPH assay. The recovered extract was previously weighed, concentrated at low temperature until removing the ethanol, lyophilized, and weighed again and the liquid recovered and the extraction yield (EY) were calculated according to Eqs. 2 and 3 respectively.

Liquid recovered $(\%)=\mathrm{W}_{\mathrm{LE}} / \mathrm{W}_{\text {solvent }} \times 100$

where $\mathrm{W}_{\mathrm{LE}}$ is the weight of the liquid extract recovered after the extraction and $\mathrm{W}_{\text {solvent }}$ is the weight of the solvent initially used, both in grams.

$\mathrm{EY}(\%)=\mathrm{W}_{\mathrm{DE}} / \mathrm{W}_{\mathrm{S}} \times 100$

where $\mathrm{W}_{\mathrm{DE}}$ and $\mathrm{W}_{\mathrm{S}}$ are the weight of the lyophilized extract and grams of dried material submitted to the extraction respectively.

A sample of the lyophilized extract was re-dissolved in water and the TPC, IC50 (inhibitory concentration of the sample required to reduce $50 \%$ of DPPH), and Trolox equivalent antioxidant capacity were determined (Section 2.3). 


\subsection{Analytical methods}

\subsubsection{Evaluation of chemical composition}

Proximate analysis (moisture, crude protein, fiber, and ash content) was determined according to [30]. Lipids were determined according to [31].

Total extractives were determined sequentially with deionized water and ethanol 98\% using a Soxhlet apparatus [32]. Klason lignin was determined according to ANSI/ ASTM [33]. Holocellulose content of the raw material was determined according to Browning (1967) [34] and cellulose was determined using ANSI/ASTM [35]. Hemicellulose was calculated as the difference between holocellulose and cellulose. In addition, total starch content was measured according to AOAC Method 996.11 using the Total Starch Assay Kit (AA/AMG) (Megazyme). The tests were performed in triplicate and all determinations were carried out both to the raw and extractive-free materials.

\subsubsection{Extractable polyphenols}

Extractable polyphenols were obtained according to [36]. $0.5 \mathrm{~g}$ of sample was extracted with $20 \mathrm{~mL}$ of methanol/water (50:50, v/v; $\mathrm{pH} 2$ ) acidified with $2 \mathrm{~N} \mathrm{HCl}$. The tube was vortexed at room temperature for 3 min then mildly shaken for $1 \mathrm{~h}$ at room temperature. Then, the sample was centrifuged at $3000 \mathrm{rpm}$ for $10 \mathrm{~min}$ and the supernatant recovered. Twenty milliliters of acetone/water (70:30, v/v) was added to the residue, and the vortexing, shaking, and centrifugation steps were repeated. The methanol and acetone extracts were combined, the volume adjusted to $50 \mathrm{~mL}$ and filtered. The extract was used to the quantification of the total phenolic compounds by the Folin-Ciocalteu method. Extractions were performed in two different replicates of each feedstock. The total phenolic compounds extracted under this procedure were considered as the maximum amount of polyphenols that could be extracted.

\subsubsection{Determination of the total phenolic compounds - Folin-Ciocalteu method}

The total phenolic content (TPC) of the extracts was determined using the Folin-Ciocalteu colorimetric method, described by [37]. A $0.5-\mathrm{mL}$ volume of blank, standard, or extract was placed into a $25-\mathrm{mL}$ assay tube to which was added $5 \mathrm{~mL}$ of distilled water and $0.5 \mathrm{~mL}$ Folin Ciocalteu reagent. The mixture was allowed to stand for $5 \mathrm{~min}$ in darkness at room temperature; after that, $10 \mathrm{~mL}$ of $75 \mathrm{~g} / \mathrm{L}$ sodium carbonate solution and $9 \mathrm{~mL}$ of distilled water were added. The mixture was vortexed and incubated for $1 \mathrm{~h}$ at room temperature in darkness. The absorbance was determined at $750 \mathrm{~nm}$ using a spectrophotometer (Cary $60 \mathrm{UV}-\mathrm{Vis}$ Agilent
Technologies). Quantification was done with respect to the standard of gallic acid in the corresponding solvent mixture. The results were expressed as gallic acid equivalents (GAE) in $\mathrm{mg}$ per $100 \mathrm{~g}$ of dried material.

\subsubsection{Determination of antioxidant activity — DPPH}

In vitro antioxidant activity was calculated using 2,2-diphenyl-1-picrylhydrazy (DPPH) assay according to [38] with minor modifications. For the determination of the radical scavenging activity, $1950 \mu \mathrm{L}$ of DPPH solution $(0.06 \mathrm{mM}$ in methanol) was added to $50 \mu \mathrm{L}$ of blank, sample extract, or standard (Trolox). The mixture was stirred and then incubated in the absence of light at room temperature for $30 \mathrm{~min}$. Then, the absorbance was measured at the wavelength of $515 \mathrm{~nm}$ and the below equation was used to calculate the DPPH activity, expressed in percentage:

DPPH Inhibition $(\%)=\left(A_{C}-A_{S}\right) / A_{C} \times 100$

where $A_{C}$ is the absorbance of blank solution containing water and DPPH and $\mathrm{A}_{\mathrm{S}}$ is the absorbance of the solution containing DPPH with the extract.

On the other hand, Trolox equivalent antioxidant capacity (TEAC) was calculated based on the Trolox calibration curve and expressed as $\mathrm{mg}$ Trolox equivalent per $\mathrm{g}$ of dried material (mg eq. Trolox/gdm).

The equation of the straight line obtained from the DPPH Inhibition (\%) values (y axis) of increasing concentrations (x axis) of re-dissolved lyophilized extracts was used for the calculation of IC50 (inhibitory concentration of the sample required to reduce $50 \%$ of $\mathrm{DPPH}$ ) for the different fractions.

\section{Results}

\subsection{Chemical composition}

Proximate analysis of rachis and BPP, both of lignocellulosic nature, and banana reflected a high content in carbohydrates, upper than $50 \%$ for all the materials. The content in lipids was practically zero and the protein levels were low, although slightly higher in the case of the rachis. Content in proteins determined for the rachis in this study was slightly higher than previously reported values: $3.30 \%$ [39], $2.0 \%$ [5]. Carbohydrate fraction of the rachis was mainly composed by cellulose and hemicellulose. In the case of BPP, apart from these two components, a high content in starch was also observed. Guerrero et al. reported a similar content of starch (20.1\%) for the pseudostem [40]. The values of hemicellulose and cellulose contents obtained for both materials are low in comparison with other herbaceous biomasses [41]. In the case of cellulose, it is usually higher 
in the stem of vascular plants, but rachis and pseudostem are not real stems. The values of both components (cellulose and hemicellulose) determined in this study are in the range obtained by other studies [42], although relatively high differences between these studies can be found. Those differences can be attributed to real variations in the composition but also to the protocols employed in the characterization, which reflects that the compositional analysis of biomass is still a challenging task [43] and that standardized protocols that minimize the errors resulting from the approaches assumed are needed.

Discarded banana presented a content in starch close to $60 \%$, similar to data found in literature (52.22\%) [44]. Due to the high presence of starch, the filtration step needed in holocellulose determination could not be carried out and, as a consequence, cellulose and hemicellulose contents could not be determined (reason why these results are not included in Table 1).

Especially interesting is the low content in lignin obtained for the two lignocellulosic materials, which were much lower than common contents found in herbaceous biomasses [45]. The determined lignin contents for both materials are in the range obtained by other studies: close to $10 \%$ for rachis [5, 42] and between 4.70 [46] and 12\% [47] for the entire banana's pseudostem. In the case of the banana, lignin content was very low and this was probably mostly present in the peels. For example, Oliveira et al. presented a content of lignin of $16.77 \%$ for banana peel [48].

Ash contents of BPP, and specially of rachis, were high, as reported by other authors [42] This high presence of ashes, not common for annual plants, has been related to nutrient transport along the plant [5]. A high extractive content was also obtained for both materials, composed, in large part, of ashes, as demonstrated in the extractive free material analysis (data not shown). The high content in extractable has also been highlighted by other authors for rachis and pseudostem [49]. In the case of the banana, extractive content was also very high, probably due to the presence of free

Table 1 Chemical composition of rachis, discarded banana, and BPP (\% w/w, dry basis)

\begin{tabular}{lrlr}
\hline Component & \multicolumn{1}{l}{ Rachis } & Discarded banana & \multicolumn{1}{l}{ BPP } \\
\hline Lipids & $1.82 \pm 0.10$ & $1.53 \pm 0.54$ & $1.19 \pm 0.54$ \\
Protein & $11.44 \pm 0.34$ & $4.57 \pm 0.251$ & $5.88 \pm 1.82$ \\
Ashes & $30.47 \pm 0.75$ & $7.4654 \pm 0.35$ & $15.44 \pm 0.05$ \\
Extractives & $31.84 \pm 1.21$ & $45.62 \pm 4.81$ & $21.11 \pm 0.79$ \\
Starch & $0.00 \pm 0.00$ & $56.64 \pm 1.61$ & $23.73 \pm 0.40$ \\
Klason lignin & $9.71 \pm 0.21$ & $4.25 \pm 0.15$ & $7.92 \pm 0.27$ \\
Cellulose & $30.15 \pm 0.81$ & - & $26.29 \pm 2.10$ \\
Hemicellulose & $15.36 \pm 2.06$ & - & $19.11 \pm 2.31$ \\
TPC $(\mathrm{mg} / 100 \mathrm{~g})$ & $1110.46 \pm 8.59$ & $823.42 \pm 27.93$ & $408.61 \pm 8.61$ \\
\hline
\end{tabular}

sugars and some extractable starch. The content in ashes for banana was lower than for the other two fractions, although higher than found in the literature (1.37\%) [44].

Comparing the three materials, the rachis had the highest amount of polyphenols, followed by the discarded bananas, and finally the BPP. Pérez-Jiménez et al. [50] identified the 100 richest dietary sources of polyphenols and found contents varying from $15,000 \mathrm{mg} / 100 \mathrm{~g}$ in cloves to $10 \mathrm{mg} / 100 \mathrm{ml}$ in rose wine. The three materials under study in the present work present a content in antioxidants included in this rank, concretely in the top-35, position ranked by the plum with a TPC of $411 \mathrm{mg} / 100 \mathrm{~g}$ (determined by the Folin assay) and $377 \mathrm{mg} / 100 \mathrm{~g}$ (determined by chromatography and direct-phase high-performance liquid chromatography). In conclusion, these results place the three by-products as good candidates for the obtaining of natural antioxidants.

Although antioxidant identification through high performance liquid chromatography (HPLC) has not been carried out in the present work, some references have been found in the literature conducting this analysis. For example, Saravanan et al. detected the presence of tannic, pyrocatechol, catechol, gentisic, (b)-catechin, protocatechuic, gallic, caffeic, chlorogenic, ferulic, and cinnamic acids in the extracts obtained from the banana's pseudostem [51]. Aboul-Enein et al., for their part, found high amounts of chrysin, quercetin, catchin, cianamic, caffeic, and coumarin in the banana skin [52]. Regarding banana fruit, its bioactive compounds and health benefits associated to them have been widely studied [53].

\subsection{Optimization of extraction conditions: temperature and ethanol concentration}

Solvent extraction was used to obtain phenolic compounds with antioxidant activity from the three different fractions under study. There are a wide number of variables involved in the efficiency of this process such as the type and concentration of solvent, the solid-to-solvent ratio, the temperature, or the time. Regarding the kind of solvent, ethanol was chosen due to the previously mentioned advantages [29]. The solid-to-solvent ratio was fixed in 1:20 (allowing a good agitation for all the by-products) for all the experiment, as it was expected to have less influence [54]. On the other hand, although it could be interesting to analyze the interaction among all the factors, in this study, the influence of the concentration of ethanol-water and the temperature was evaluated in a first moment. Then, the influence of the time was studied. The time was therefore initially fixed in $1 \mathrm{~h}$ and the other two variables were varied as shown in Table 2 .

Table 2 shows the mean values of the phenolic content and antioxidant activity for the extracts obtained under the different conditions tested working with the three 
Table 2 Total phenolic content (TPC) and in vitro antioxidant activity (DPPH inhibition) of rachis, discarded banana, and BPP extracts obtained using a solvent extraction (solid-to-solvent ratio of 1:20 and time of extraction of $60 \mathrm{~min}$ ) under different conditions of ethanol concentration and temperature

\begin{tabular}{|c|c|c|c|c|c|c|c|}
\hline \multicolumn{2}{|c|}{ Conditions } & \multicolumn{2}{|l|}{ Rachis } & \multicolumn{2}{|l|}{ Discarded banana } & \multicolumn{2}{|l|}{ BPP } \\
\hline $\mathrm{T}\left({ }^{\circ} \mathrm{C}\right)$ & Et-OH $(\%)$ & TPC $(\mathrm{mg} / 100 \mathrm{~g})$ & $\begin{array}{l}\text { DPPH inhibition } \\
(\%)\end{array}$ & TPC $(\mathrm{mg} / 100 \mathrm{~g})$ & $\begin{array}{l}\text { DPPH inhibition } \\
(\%)\end{array}$ & TPC (mg/100 g) & DPPH inhibition (\%) \\
\hline \multirow[t]{5}{*}{24} & 0 & $297.26^{\mathrm{bc}} \pm 1.22$ & $32.99^{\mathrm{ac}} \pm 2.18$ & $112.99^{\mathrm{b}} \pm 15.07$ & $10.96^{\mathrm{ab}} \pm 1.18$ & $96.37^{\mathrm{a}} \pm 17.55$ & $7.98^{\mathrm{ab}} \pm 1.35$ \\
\hline & 20 & $330.49^{\text {bd }} \pm 3.15$ & $51.24^{\mathrm{bcd}} \pm 0.12$ & $154.19^{\mathrm{bc}} \pm 1.00$ & $26.26^{\mathrm{c}} \pm 0.33$ & $124.50^{\mathrm{ac}} \pm 14.08$ & $12.88^{b c} \pm 0.39$ \\
\hline & 40 & $489.99^{\mathrm{fg}} \pm 29.86$ & $86.79^{\mathrm{d}} \pm 0.12$ & $206.05^{\mathrm{cd}} \pm 3.43$ & $62.79^{\mathrm{e}} \pm 0.30$ & $171.57^{\mathrm{ad}} \pm 6.11$ & $20.90^{\mathrm{e}} \pm 0.49$ \\
\hline & 60 & $519.69^{\mathrm{gh}} \pm 4.26$ & $87.17^{\mathrm{d}} \pm 0.27$ & $415.99^{g} \pm 18.76$ & $91.27^{\mathrm{h}} \pm 1.22$ & $227.77^{\text {bcdf }} \pm 30.55$ & $19.08^{\mathrm{de}} \pm 0.17$ \\
\hline & 100 & $23.39^{\mathrm{a}} \pm 1.72$ & $0.9^{\mathrm{a}} \pm 0.20$ & $0.00^{\mathrm{a}} \pm 0.00$ & $4.32^{\mathrm{a}} \pm 0.25$ & $116.58^{\mathrm{ab}} \pm 8.29$ & $3.90^{\mathrm{a}} \pm 0.11$ \\
\hline \multirow[t]{3}{*}{50} & 20 & $381.90^{\text {cde }} \pm 14.92$ & $49.30^{\mathrm{bcd}} \pm 0.28$ & $256.54^{\mathrm{df}} \pm 2.24$ & $39.65^{\mathrm{d}} \pm 2.94$ & $160.61^{\mathrm{ad}} \pm 30.62$ & $12.00^{\mathrm{bc}} \pm 0.33$ \\
\hline & 40 & $606.34^{\mathrm{hi}} \pm 21.32$ & $85.33^{\mathrm{d}} \pm 0.15$ & $277.80^{\mathrm{ef}} \pm 0.65$ & $73.96^{\mathrm{f}} \pm 1.93$ & $220.21^{\mathrm{cdf}} \pm 37.11$ & $18.61^{\mathrm{de}} \pm 1.23$ \\
\hline & 60 & $702.57^{\mathrm{ij}} \pm 30.41$ & $87.21^{\mathrm{d}} \pm 0.28$ & $285.61^{\mathrm{f}} \pm 9.05$ & $77.92^{\mathrm{fg}} \pm 5.47$ & $245.07^{\mathrm{df}} \pm 34.70$ & $22.23^{\mathrm{e}} \pm 0.52$ \\
\hline \multirow[t]{8}{*}{78} & 0 & $248.99^{\mathrm{b}} \pm 9.89$ & $27.15^{\mathrm{ab}} \pm 0.21$ & $228.75^{\mathrm{de}} \pm 18.72$ & $17.74^{\mathrm{bc}} \pm 4.10$ & $115.22^{\mathrm{ab}} \pm 30.72$ & $9.42^{\mathrm{b}} \pm 0.36$ \\
\hline & 20 & $406.47^{\mathrm{df}} \pm 49.23$ & $48.19^{\mathrm{bcd}} \pm 2.82$ & $518.77^{\mathrm{hi}} \pm 5.58$ & $75.07^{\mathrm{f}} \pm 4.34$ & $247.10^{\mathrm{cdf}} \pm 18.73$ & $19.33^{\mathrm{de}} \pm 0.00$ \\
\hline & 40 & $678.63^{\mathrm{i}} \pm 52.65$ & $85.61^{\mathrm{d}} \pm 0.12$ & $418.59^{g} \pm 32.89$ & $90.87^{\mathrm{h}} \pm 0.10$ & $277.57^{\mathrm{df}} \pm 23.33$ & $30.34^{\mathrm{f}} \pm 0.69$ \\
\hline & 50 & $699.24^{\mathrm{ij}} \pm 22.09$ & $86.49^{\mathrm{d}} \pm 0.22$ & $558.45^{\mathrm{i}} \pm 5.17$ & $89.91^{\mathrm{h}} \pm 0.16$ & $318.77^{\mathrm{ef}} \pm 39.82$ & $35.46^{\mathrm{fg}} \pm 0.15$ \\
\hline & 60 & $796.40^{\mathrm{j}} \pm 18.20$ & $87.22^{\mathrm{d}} \pm 0.27$ & $479.16^{\mathrm{h}} \pm 19.68$ & $91.31^{\mathrm{h}} \pm 0.26$ & $353.65^{\mathrm{f}} \pm 55.68$ & $36.19^{g} \pm 2.49$ \\
\hline & 70 & - & - & - & - & $347.55^{\mathrm{f}} \pm 55.56$ & $32.74^{\mathrm{fg}} \pm 0.79$ \\
\hline & 80 & $504.83^{\mathrm{efh}} \pm 36.5$ & $80.91^{\mathrm{d}} \pm 0.31$ & $396.80^{\mathrm{g}} \pm 1.12$ & $85.07^{\mathrm{gh}} \pm 0.55$ & - & - \\
\hline & 100 & $120.80^{\mathrm{a}} \pm 3.37$ & $20.43^{\mathrm{bcd}} \pm 3.26$ & $104.73^{\mathrm{b}} \pm 11.50$ & $20.13^{b c} \pm 2.22$ & $191.12^{\text {ad }} \pm 16.77$ & $15.20^{\mathrm{cd}} \pm 4.67$ \\
\hline
\end{tabular}

Values are means of duplicate determinations \pm SD. Mean values followed by different superscript in a column are significantly different $(\mathrm{p}<0.05)$

by-products. For the three materials, the amount of extracted polyphenols obtained under all the tested conditions was lower than the total extractable polyphenols (Table 1), determined according to the procedure described in Section 2.3.2. This is due to the use of solvents of different nature (methanol/water and acetone/water), so more compounds could be solubilized. For example, methanol has been generally found to be more efficient in the extraction of lower molecular weight polyphenols, whereas aqueous acetone is good for extraction of higher molecular weight flavanols [55].

The $\mathrm{p}$ values obtained from the ANOVA test (Table 3) reflected that the concentration of ethanol had a great impact on the two responses analyzed for all the materials. Also the temperature exhibited a highly significant effect on the extraction in all cases; only for DPPH inhibition response of the rachis, the $\mathrm{p}$ value was slightly higher (0.0739) than 0.05 , although it can be due to the high values obtained in that response and so difference could not be detected. Interaction effects between the two variables were significant in some cases.

The experimental data for the two responses (TPC and DPPH inhibition) presented a good fit to a second-order polynomial model. In Table 4 , the estimated regression coefficients and the coefficient of determination $\left(\mathrm{R}^{2}\right)$ are given. A satisfactory coefficient of determination, higher than 0.85 in all cases, was obtained for all the fittings (Table 4). The fitting parameters (linear terms) of the models, shown in Table 4, reflect that the ethanol concentration has a greater impact (positive impact) on the polyphenol extraction than the temperature. On the other hand, the temperature had, in general, a negative effect on the response. If the quadratic coefficients are analyzed, the variable representing ethanol concentration has a negative coefficient in all cases meaning that the response has
Table 3 p values obtained from the ANOVA test

\begin{tabular}{|c|c|c|c|c|c|c|}
\hline \multicolumn{7}{|c|}{$\mathrm{p}$ values (ANOVA) } \\
\hline & \multicolumn{2}{|l|}{ Rachis } & \multicolumn{2}{|c|}{ Discarded banana } & \multicolumn{2}{|l|}{ BPP } \\
\hline & TPC & DPPH & TPC & DPPH & TPC & DPPH \\
\hline $\mathrm{T}$ & 0 & 0.0739 & $1.74206 \mathrm{E}-9$ & $8.1604 \mathrm{E}-8$ & 0.0003 & $3.756 \mathrm{E}-12$ \\
\hline$\% \mathrm{EtOH}$ & 0 & 0 & $2.83912 \mathrm{E}-6$ & $2.4780 \mathrm{E}-9$ & 0.0014 & $7.934 \mathrm{E}-12$ \\
\hline Interaction & 0.0133 & 0.2937 & $1.21194 \mathrm{E}-6$ & $5.5540 \mathrm{E}-6$ & 0.8355 & $2.7668 \mathrm{E}-7$ \\
\hline
\end{tabular}


Table 4 Coefficient of determination $\left(\mathrm{R}^{2}\right)$ and estimated regression coefficients of the second-order polynomial equation $\mathrm{f}(\mathrm{T}$, $\% \mathrm{Et}-\mathrm{OH})=\mathrm{p} 00+\mathrm{p} 10 * \mathrm{~T}+\mathrm{p} 01 * \% \mathrm{Et}-\mathrm{OH}+\mathrm{p} 20 * \mathrm{~T}^{2}+\mathrm{p} 11 * \mathrm{~T} * \% \mathrm{Et}-$
$\mathrm{OH}+\mathrm{p} 02 * \% \mathrm{Et}-\mathrm{OH}^{2}$ obtained from the adjustment of the experimental values of TPC and DPPH Inhibition obtained in the extraction of the three by-products (rachis, discarded banana, and BPP)

\begin{tabular}{lllllllll}
\hline Fraction & Response & $\mathrm{p} 00$ & $\mathrm{p} 10$ & $\mathrm{p} 01$ & $\mathrm{p} 20$ & $\mathrm{p} 11$ & $\mathrm{p} 02$ & $\mathrm{R}^{2}$ \\
\hline Rachis & TPC & 113.6 & 2.295 & 16.55 & -0.01301 & 0.02864 & -0.1883 & 0.8692 \\
& DPPH & 37.96 & -0.6456 & 2.42 & 0.00452 & 0.005755 & -0.0275 & 0.9155 \\
\multirow{2}{*}{ Banana } & TPC & 196.1 & -9.682 & 11.85 & 0.1375 & -0.01778 & -0.1182 & 0.852 \\
& DPPH & 11.65 & -0.9716 & 3.069 & 0.01375 & -0.0008915 & -0.02924 & 0.9116 \\
BPP & TPC & 97.51 & -2.765 & 5.833 & 0.04077 & 0.00891 & -0.05556 & 0.9155 \\
& DPPH & 18.53 & -0.8084 & 0.6807 & 0.008791 & 0.002175 & -0.00753 & 0.9429 \\
\hline
\end{tabular}


Fig. 1 Response surface showing the effect of temperature and solvent fraction on the total phenolic content (left) and the antioxidant activity (right) of rachis extract
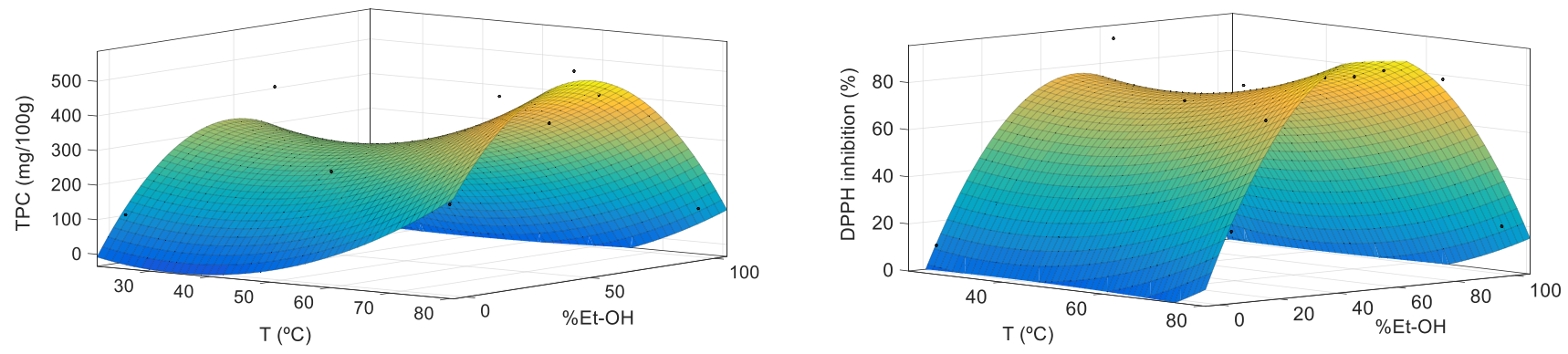

Fig. 2 Response surface showing the effect of temperature and solvent fraction on the total phenolic content (left) and the antioxidant activity (right) of banana extract


Fig. 3 Response surface showing the effect of temperature and solvent fraction on the total phenolic content (left) and the antioxidant activity (right) of BPP extract 
a maximum value also observed in Figs. 1, 2, and 3 and so optimization analysis can be performed. In the case of the temperature, however, it has a positive quadratic coefficient.

Figures 1, 2 and 3 show the representations obtained for TPC and DPPH inhibition for rachis, banana, and BPP. The experimental points are also represented to show the deviation between the model and the values observed. Both variables presented quite similar surface responses among them. The representations obtained for BPP and banana are quite similar but differ from the ones obtained for the rachis.

The optimal conditions were determined using the fitted equations obtained for the two response variables (TPC and DPPH inhibition). For the three materials, the results were practically the same using both equations. Given the similarity of the results among these variables, it can be stated that phenolic compounds are responsible for the observed antioxidant activity. A regression analysis was also performed between the values of TPC and the DPPH inhibition for the three materials separately. The values of $\mathrm{R}^{2}$ obtained in the three cases were above 0.84 . This correlation suggests that phenolic compounds are likely to contribute to the radical scavenging activity of the three by-products extracts and that, in this occasion, TPC assay, despite its limitations [56], is a good predictor of the antioxidant activity. Similar results have been found before for the extracts of other lignocellulosic materials [29, 54].

Higher concentrations of polyphenols were found in the extracts obtained at high temperatures for the three materials. High temperature reduces solvent viscosity and surface tension and increases solvation power of the extraction solvent and solubility of the solute, allowing a greater diversity of active compounds to dissolve in the solvent [29]. In this occasion, maximum temperature was established in the boiling temperature of pure ethanol $\left(78^{\circ} \mathrm{C}\right)$ and the optimum of the response surface was determined within the assay range conditions, obtaining for all the materials that the optimum was at this temperature. Higher temperatures could provide better results, although the use of more complex technologies could be required and the stability of the phenolic compounds as well as the purity of the extracts should be taken into consideration.

Ethanol concentration had greater impact on the polyphenol extraction than the temperature, as already mentioned. Although it was expected that water-alcohol mixtures were more efficient than the mono-component solvent system [29], the extreme conditions were also tested to have more information for the adjustment of the data. The expected behavior was confirmed for the three by-products, showing a better response the extractions carried out with water-ethanol mixtures. On the one hand, the hydrophilic nature of the hydroxyl groups found in several phenolic compounds [29], as well as the presence of sugars attached to the molecules of many phenolic compounds, increases their hydrophilicity and, as a consequence, the extraction of phenolic compounds at high concentrations of ethanol is diminished [57]. However, on the other hand, the use of pure water as solvent can be also unfavorable, as it can solubilize other kind of molecules, such as proteins and polysaccharides, especially at high temperatures, leading to a decrease in the extraction selectivity [57]. In this occasion, concentrations of ethanol close to $50 \%$ provided the better results.

Some experimental tests (see Table 2) were performed close to the predicted optimized conditions. In the case of the BPP and banana, the predicted values were very close to the observed ones. For the BPP, the maximum values of TPC and DPPH inhibition predicted were $321.6 \mathrm{mg} / 100 \mathrm{~g}$ and $32.9 \%$ respectively $\left(\mathrm{T}=78{ }^{\circ} \mathrm{C}\right.$ and $\left.\approx 60 \% \mathrm{Et}-\mathrm{OH}\right)$ and in the case of the banana were $509 \mathrm{mg} / 100 \mathrm{~g}$ and $96.4 \%$ $\left(\mathrm{T}=78{ }^{\circ} \mathrm{C}\right.$ and $\approx 50 \%$ Et-OH). In both cases, the experimental observed values (shown in Table 2) working under the same conditions presented less than $10 \%$ of deviation than the predicted values. The optimal experimental values of TPC corresponded to a yield in polyphenol extraction of $86.55 \%$ and $67.82 \%$ regarding total TPC (shown in Table 1) and a TEAC of $3.00 \mathrm{mg}$ eq. Trolox $/ \mathrm{gdm}$ and $6.30 \mathrm{mg}$ eq. Trolox/gdm for BPP and banana respectively. In the case of the rachis, the model predicted the optimum at a concentration of 50\%, while the maximum observed yield in polyphenol extraction was $71.72 \%$ and $6.51 \mathrm{mg}$ eq. Trolox/gdm, corresponding to a concentration of $60 \%$. In fact, Tukey test did not find significant differences between the values obtained for $50 \%$ and $60 \%$ ethanol concentrations (both values have the same superscript in Table 2).

The results found in this work are somewhat in accordance with those obtained previously for other lignocellulosic materials. For example, Fernández-Argullo et al. obtained that the extraction of walnut shavings with $50 \%$ ethanol concentration at $80{ }^{\circ} \mathrm{C}$ and $30 \mathrm{~min}$ led to the extracts with the greater TPC and antioxidant activities [54], or Xavier et al. found that the optimum conditions using by-products generated in forestry were $75^{\circ} \mathrm{C}, 55 \mathrm{~min}$, and an ethanol concentration of 30\% [29].

\subsection{Influence of the extraction time}

Once the optimal conditions (temperature and ethanol concentration) were determined for each feedstock, the influence of the time of extraction under these conditions was also tested. The objective was not the development of the kinetic models but the determination of the minimum time needed while keeping, at the same time, the yield in the extraction of polyphenols. Figure 4 shows the obtained results for the different by-products.

Big differences between the tested times were not found. In general, at $15 \mathrm{~min}$, the polyphenol concentrations were slightly slower. On the other hand, long extraction times were not helpful to increase the yield of polyphenols. The 




Fig. 4 Time-evolution of the total phenolic content (TPC) in the extracts obtained under the optimized conditions of the three by-products (rachis, discarded banana, and BPP)

observed behavior is typical for solid-liquid extraction curves, with a very quick initial stage followed, in a few minutes, by a rather slow stage, where the extraction yield increases slowly with time until reaching a constant value corresponding to equilibrium [29].

On the other hand, prolonged extraction time can cause chemical decomposition of the bioactive compounds present in the extract, diminishing extract antioxidant properties. For example Huang et al. (2009) found that more than 70 min can be harmful to the extract [58]. In this occasion, the extracted antioxidants remain quite stable during the studied conditions. The same behavior was observed in the case of DPPH inhibition values (data not shown).

Based on the results obtained, the conditions chosen for rachis and BPP were $60 \%$ of Et-OH concentration, $78{ }^{\circ} \mathrm{C}$, and $30 \mathrm{~min}$ of extraction time; in the case of the discarded banana, $50 \%$ of Et-OH concentration, $78{ }^{\circ} \mathrm{C}$, and $60 \mathrm{~min}$. Shorter times could be used in order to minimize the energy cost of the process. However, as observed in Fig. 4, shorter time assays provided the higher deviations in results (these are even not observed for longer periods, as results are quite close between replicates). This may be due to the influence of the heating period, more relevant for shorter times than for longer ones.

\subsection{Determination of the extraction yields and characterization of the extracts}

Finally, under the operational conditions selected for each material (temperature, ethanol concentration, and time), experiments were carried out at a larger scale in order to calculate the extraction yields and to characterize the obtained extracts. The percentage of extract recovered (Eq. 2) and extraction yield (Eq. 3) were calculated as well as the TPC in the extract, the IC50, and the TEAC (Table 5).

Although not shown in Table 5, the values of TPC (mg GAE/100 $\mathrm{g}$ of dried plant) measured directly in the extract (before lyophilisation) were slightly lower with respect to the small-scale experiments. This can be due to the difference between the recipients used and consequently in agitation efficiency and mass transfer, among others factors.

The values of percentage of liquid recuperation for rachis and BPP were similar and higher than for discarded banana. In the case of banana, the extract presented a slimy consistency that hampered the filtration and made that more liquid remained retained in the solid. With regard to the extraction yields, the values are affected by the liquid recovery, which can be improved by a washing stage. If all the extract had been recovered, values of EY of $35.64 \%$ for the rachis, $14.68 \%$ for the banana, and $22.1 \%$ for the BPP had been achieved.

On the other hand, if the values of TPC measured directly in the liquid extracts (expressed as $\mathrm{mg} / 100 \mathrm{~g}$ of dried plant) and the values of TPC of the re-dissolved extract (expressed as $\mathrm{mg} / \mathrm{g}$ extract) are compared, it can be seen that, while the first values (Table 2) are higher for the rachis, the second ones (Table 5) are higher for the discarded banana. This is due to the higher solubilization arising for the rachis (as reflected by EY values) and so, a less pure extract was obtained in the case of the rachis.

For all the materials, a linear relationship between the antioxidant concentration and the DPPH radical scavenging activity was obtained, which made the determination of the IC50 values simple. The values obtained for IC50 are in accordance with the values of TPC: the higher the TPC, the less the concentration required to obtain a $50 \%$ antioxidant effect.

Trolox equivalents/g of extract) of the lyophilized extracts obtained under the optimal conditions determined for the three by-products

Liquid recovered, extraction yield (EY), and total phenol content (TPC) IC50 (concentration required to obtain a 50\% antioxidant effect) and TEAC (Trolox equivalent antioxidant capacity, mg

\begin{tabular}{llrrrr}
\hline Fraction & Liquid recovered $(\%)$ & \multicolumn{1}{c}{ EY $(\%)$} & TPC $(\mathrm{mg} / \mathrm{g}$ extract) & IC50 $(\mathrm{mg} / \mathrm{mL})$ & TEAC $(\mathrm{mg} / \mathrm{g}$ extract) \\
\hline Rachis & $72.93 \pm 4.08$ & $26.00 \pm 1.72$ & $22.52 \pm 1.07$ & $3.90 \pm 0.16$ & $42.50 \pm 1.89$ \\
Discarded banana & $65.64 \pm 2.64$ & $9.63 \pm 0.04$ & $27.26 \pm 1.30$ & $3.03 \pm 0.14$ & $54.59 \pm 3.20$ \\
BPP & $73.11 \pm 1.76$ & $16.15 \pm 0.40$ & $10.17 \pm 0.20$ & $10.77 \pm 0.21$ & $15.16 \pm 0.37$ \\
\hline
\end{tabular}


Comparing with other works working with banana byproducts, for example, Loganayaki et al. [18] obtained a $21.7 \%$ extraction yield and a TPC of $12 \mathrm{mg} / \mathrm{g}$ extract using banana stem (Musa paradisiaca) methanol extract. In a previous study, Gonzalez-Montelongo et al. [59] reported a TPC of $12-19 \mathrm{mg} / \mathrm{g}$ extract in the methanolic extracts obtained from banana peels and values of around $20 \mathrm{mg}$ Trolox equivalents/g of extract. Not only extraction methods but also different procedures adopted for TPC analysis are likely to give different results. Besides, total phenolic concentration can be influenced by geographical origin, cultivar, harvest and storage time, and drying [60].

The results obtained in this study are comparable with the obtained working with other agricultural residues. For example, Babbar et al. obtained a TPC of $37.4 \mathrm{mg} / \mathrm{g}$ and $42.23 \mathrm{mg}$ Trolox eq./g extract using grape seed [60]. Karabegović et al., for their part, got Solanum retroflexum fruit extracts with $92.07 \mathrm{mg}$ of gallic acid/g extract under extraction with $75 \% \mathrm{Et}-\mathrm{OH}, 60{ }^{\circ} \mathrm{C}$, and $45 \mathrm{~min}$ [61].

\section{Conclusions}

In this study, the optimization of the antioxidant extraction of three by-products from banana crops (rachis, discarded banana, and BPP) through a green extraction process was performed. The second-order polynomial models used for the optimization gave a satisfactory description of the experimental data. In general, ethanol concentration had the greatest impact on the polyphenol extraction and concentrations close to $50 \%$ for the three materials led to the better results. The highest tested temperature $\left(78^{\circ} \mathrm{C}\right)$ gave the best results in all cases; the extract properties were less affected by the extraction time. Among the three materials, the rachis extracts presented the highest polyphenolic content per gram of raw material, followed by discarded banana, and finally BPP.

The experiments carried out at larger scale under the optimal conditions allowed to obtain values of TPC of $27.26 \mathrm{mg} / \mathrm{g}$ extract for discarded bananas $(50 \% \mathrm{Et}-\mathrm{OH}, 78$ ${ }^{\circ} \mathrm{C}$, and $60 \mathrm{~min}$ ) and $22.52 \mathrm{mg} / \mathrm{g}$ and $10.17 \mathrm{mg} / \mathrm{g}$ for rachis and BPP respectively $\left(60 \% \mathrm{Et}-\mathrm{OH}, 78{ }^{\circ} \mathrm{C}\right.$, and $30 \mathrm{~min}$ for both materials). Although the concentration obtained for lyophilized banana extract was slightly higher in the case of discarded banana, the extraction yield obtained in the case of the rachis was nearly three times higher and so, it would allow to obtain much more polyphenolic compounds processing the same amount of raw material.

The results obtained in this study demonstrate that the banana crop residues under study, and specially the rachis, might constitute a good source of phenolic compounds with antioxidant capacity that could be used in different industrial applications.
Funding Open Access funding provided thanks to the CRUE-CSIC agreement with Springer Nature. The financial support for developing this research work was supplied by the Ministry of Education, Culture and Sports of Spain, (Grant Ref. FPU15/03138).

\section{Declarations}

Competing interests The authors declare no competing interests.

Open Access This article is licensed under a Creative Commons Attribution 4.0 International License, which permits use, sharing, adaptation, distribution and reproduction in any medium or format, as long as you give appropriate credit to the original author(s) and the source, provide a link to the Creative Commons licence, and indicate if changes were made. The images or other third party material in this article are included in the article's Creative Commons licence, unless indicated otherwise in a credit line to the material. If material is not included in the article's Creative Commons licence and your intended use is not permitted by statutory regulation or exceeds the permitted use, you will need to obtain permission directly from the copyright holder. To view a copy of this licence, visit http://creativecommons.org/licenses/by/4.0/.

\section{References}

1. Mohapatra D, Mishra S, Sutar N (2010) Banana and its by-product utilisation: an overview. J Sci Ind Res 69:323-329

2. FAO FAO - Food and Agriculture Organization of the United Nations. Banana facts and figures. http://www.fao.org/economic/ est/est-commodities/bananas/bananafacts/en/\#.XnuyXoj7TIV. Accessed 25 Mar 2020

3. ASPROCAN Asociación de Organizaciones de Productores de Plátanos de Canarias (ASPROCAN). Estadísticas de producción y comercialización de Plátano de Canarias. 2018. https://plata nodecanarias.es/wp-content/uploads/2019/03/DossierPDC_2018. pdf. Accessed 25 Mar 2020

4. Souza EL, Liebl GF, Marangoni C et al (2014) Bioethanol from fresh and dried banana plant pseudostem. Chem Eng Trans 38:271-276. https://doi.org/10.3303/CET1438046

5. Oliveira L, Cordeiro N, Evtuguin DV et al (2007) Chemical composition of different morphological parts from 'Dwarf Cavendish' banana plant and their potential as a non-wood renewable source of natural products. Ind Crops Prod 26:163-172. https://doi.org/ 10.1016/J.INDCROP.2007.03.002

6. Mokbel MS, Hashinaga F (2005) Antibacterial and antioxidant activities of banana (Musa, AAA cv. Cavendish) fruits peel. Am J Biochem Biotechnol 1:125-131. https://doi.org/10.3844/ajbbsp.2005.125.131

7. Awele Okolie J, Henry OE, Epelle EI (2016) Determination of the antioxidant potentials of two different varieties of banana peels in two different solvents. Food Nutr Sci 07:1253-1261. https://doi. org/10.4236/fns.2016.713115

8. Sundaram S, Anjum S, Dwivedi P, Rai GK (2011) Antioxidant activity and protective effect of banana peel against oxidative hemolysis of human erythrocyte at different stages of ripening. Appl Biochem Biotechnol 164:1192-1206. https://doi.org/10. 1007/s12010-011-9205-3

9. Devatkal SK, Kumboj R, Paul D (2014) Comparative antioxidant effect of BHT and water extracts of banana and sapodilla peels in raw poultry meat. J Food Sci Technol 51:387-391. https://doi. org/10.1007/s13197-011-0508-8 
10. Anal AK, Jaisanti S, Noomhorm A (2014) Enhanced yield of phenolic extracts from banana peels (Musa acuminata Colla AAA) and cinnamon barks (Cinnamomum varum) and their antioxidative potentials in fish oil. J Food Sci Technol 51:2632-2639. https://doi.org/10.1007/s13197-012-0793-x

11. Bennett RN, Shiga TM, Hassimotto NMA et al (2010) Phenolics and antioxidant properties of fruit pulp and cell wall fractions of postharvest banana (Musa acuminata Juss.) cultivars. J Agric Food Chem 58:7991-8003

12. Saravanan K, Aradhya SM (2011) Potential nutraceutical food beverage with antioxidant properties from banana plant bio-waste (pseudostem and rhizome). Food Funct 2:603-610. https://doi.org/ 10.1039/c1fo10071h

13. Kandasamy S, Baggu C, Javagal MR et al (2014) Antioxidant properties of isolated compounds from banana rhizome. J Food Sci 79:H988-H1001. https://doi.org/10.1111/1750-3841.12414

14. Padam BS, Tin HS, Chye FY, Abdullah MI (2012) Antibacterial and antioxidative activities of the various solvent extracts of banana (Musa paradisiaca cv. Mysore) inflorescences. J Biol Sci 12:62-73. https://doi.org/10.3923/jbs.2012.62.73

15. Schmidt MM, Prestes RC, Kubota EH et al (2015) Evaluation of antioxidant activity of extracts of banana inflorescences (Musa cavendishii). CyTA - J Food 13(4):498-505. https://doi.org/10. 1080/19476337.2015.1007532

16. Bhaskar JJ, M S, Chilkunda ND, Salimath PV (2012) Banana (Musa sp. var. elakki bale) flower and pseudostem: dietary fiber and associated antioxidant capacity. J Agric Food Chem 60:427432. https://doi.org/10.1021/jf204539v

17. Kumar PR, Srivastava S, Kumar KK et al (2014) Study of Antioxidant and antimicrobial properties, phytochemical screening and analysis of sap extracted from banana ( Musa acuminata ) pseudostem. Int J Adv Biotechnol Res 5:649-658. https://doi.org/ 10.1023/A:1014565018160

18. Loganayaki N, Rajendrakumaran D, Manian S (2010) Antioxidant capacity and phenolic content of different solvent extracts from banana (Musa paradisiaca) and mustai (Rivea hypocrateriformis). Food Sci Biotechnol 19:1251-1258. https://doi.org/10. 1007/s10068-010-0179-7

19. Apriasari ML, Iskandar SE (2014) Bioactive compound and antioxidant activity of methanol extract mauli bananas (Musa sp) stem. Int J Biosci Biochem Bioinforma 4:110-115. https://doi. org/10.7763/ijbbb.2014.v4.321

20. Anusuya N, Gomathi R, Tharani J, Murugesan GS (2013) Impact of polyphenols from banana pseudostem on sunflower oil stability. Food Sci Biotechnol 22:773-780. https://doi.org/10.1007/ s10068-013-0144-3

21. Karuppiah P, Mustaffa M (2013) Antibacterial and antioxidant activities of Musa sp. leaf extracts against multidrug resistant clinical pathogens causing nosocomial infection. Asian Pac J Trop Biomed 3:737-742

22. Kumar Y, Yadav DN, Ahmad T, Narsaiah K (2015) Recent trends in the use of natural antioxidants for meat and meat products. Compr Rev Food Sci Food Saf 14:796-812. https://doi.org/10. $1111 / 1541-4337.12156$

23. Kebede M, Admassu S (2019) Application of antioxidants in food processing industry: options to improve the extraction yields and market value of natural products. Adv Food Technol Nutr Sci Open J 5:38-49. https://doi.org/10.17140/aftnsoj-5-155

24. Anwar H, Hussain G, Mustafa I (2018) Antioxidants from natural sources. In: Antioxidants in foods and its applications. IntechOpen. https://doi.org/10.5772/intechopen.75961

25. Hidalgo G-I, Almajano MP (2017) Red fruits: extraction of antioxidants, phenolic content, and radical scavenging determination: a review. Antioxidants 6:7. https://doi.org/10.3390/antiox6010007

26. Toh PY, Leong FS, Chang SK et al (2016) Optimization of extraction parameters on the antioxidant properties of banana waste.
Acta Sci Pol Technol Aliment 15:65-78. https://doi.org/10. 17306/J.AFS.2016.1.7

27. Šeremet D, Durgo K, Jokić S et al (2020) Valorization of banana and red beetroot peels: determination of basic macrocomponent composition, application of novel extraction methodology and assessment of biological activity in vitro. Sustainability 12:1-21

28. Díaz S, Ortega Z, Benítez AN et al (2021) Assessment of the effect of autohydrolysis treatment in banana's pseudostem pulp. Waste Manag 119:306-314. https://doi.org/10.1016/j.wasman. 2020.09.034

29. Xavier L, Freire MS, González-Álvarez J (2019) Modeling and optimizing the solid-liquid extraction of phenolic compounds from lignocellulosic subproducts. Biomass Convers Biorefinery 9:737-747. https://doi.org/10.1007/s13399-019-00401-9

30. AOAC (1995) Official methods of analysis 16th Ed. Association of official analytical chemists. Washington DC, USA. http:// www.sciepub.com/reference/141205. Accessed 25 Mar 2021

31. Folch J, Lees M, Stanley GHS (1957) A simple method for the isolation and purification of total lipides from animal tissues PubMed. J Biol Chem 226:497-509

32. Sluiter A, Hames B, Ruiz R et al (2008) Determination of structural carbohydrates and lignin in biomass: Laboratory Analytical Procedure, TP-510-42618

33. ANSI/ASTM (1977a) Standard test methods for lignin in wood D1106-56. American National Standard Institute, Washington DC. https://doi.org/10.1520/D1106-21

34. Browning B (1967) Methods of wood chemistry, vol 2. Interscience Publishers, New York

35. ANSI/ASTM (1977b) Method of Test for Alpha-Cellulose in wood ASTM D1103, 60th edn

36. Pérez-Jiménez J, Saura-Calixto F (2018) Non-extractable polyphenols and carotenoids : importance in human nutrition and health, Vol. 5. Royal Society of Chemistry

37. Singleton VL, Orthofer R, Lamuela-Raventós RM (1999) [14] Analysis of total phenols and other oxidation substrates and antioxidants by means of folin-ciocalteu reagent. Methods Enzymol 299:152-178. https://doi.org/10.1016/S0076-6879(99) 99017-1

38. Carciochi RA, Sologubik CA, Fernández MB et al (2018) Extraction of antioxidant phenolic compounds from brewer's spent grain: optimization and kinetics modeling. Antioxidants 7(4):45. https://doi.org/10.3390/antiox7040045

39. Medina DAP, Nuñez MFA, Ordoñes MS (2011) Obtención de Enzimas Celulasas por Fermentación Sólida de Hongos para ser Utilizadas en el Proceso de Obtención de Bioalcohol de Residuos del Cultivo de Banano. Revista Tecnológica - ESPOL 23(1):8188. http://www.rte.espol.edu.ec/index.php/tecnologica/article/ view/39. Accessed June 2021

40. Guerrero AB, Ballesteros I, Ballesteros M (2017) Optimal conditions of acid-catalysed steam explosion pretreatment of banana lignocellulosic biomass for fermentable sugar production. J Chem Technol Biotechnol 92:2351-2359. https://doi.org/10.1002/jctb. 5239

41. Moniz P, Pereira H, Duarte LC, Carvalheiro F (2014) Hydrothermal production and gel filtration purification of xylo-oligosaccharides from rice straw. Ind Crops Prod 62:460-465

42. Guerrero AB, Aguado PL, Sánchez J, Curt MD (2016) GISbased assessment of banana residual biomass potential for ethanol production and power generation: a case study. Waste and Biomass Valorization 7:405-415. https://doi.org/10.1007/ s12649-015-9455-3

43. Krasznai DJ, Champagne P, Cunningham MF (2012) Quantitative characterization of lignocellulosic biomass using surrogate mixtures and multivariate techniques. Bioresour Technol 110:652661. https://doi.org/10.1016/j.biortech.2012.01.089 
44. de Fontes SM, Cavalcanti MT, Candeia RA, Almeida EL (2017) Characterization and study of functional properties of banana starch green variety of Mysore (Musa AAB - Mysore). Food Sci Technol 37:224-231. https://doi.org/10.1590/1678-457X.18916

45. Patrícia M, Lino J, Duarte LC et al (2015) Fractionation of hemicelluloses and lignin from rice straw by combining autohydrolysis and optimised mild organosolv delignification. BioResources 10:2626-2641

46. Duque SH, Cardona CA, Moncada J (2015) Techno-economic and environmental analysis of ethanol production from 10 agroindustrial residues in Colombia. Energy Fuels 29:775-783

47. Thakur S, Shrivastava B, Ingale $S$ et al (2013) Degradation and selective ligninolysis of wheat straw and banana stem for an efficient bioethanol production using fungal and chemical pretreatment. 3 Biotech 3:365-372. https://doi.org/10.1007/ s13205-012-0102-4

48. Oliveira TÍS, Rosa MF, Cavalcante FL et al (2016) Optimization of pectin extraction from banana peels with citric acid by using response surface methodology. Food Chem 198:113-118. https:// doi.org/10.1016/j.foodchem.2015.08.080

49. Cordeiro N, Belgacem M, Torres I, Moura JCV (2004) Chemical composition and pulping of banana pseudo-stems. Ind Crops Prod 19:147-154. https://doi.org/10.1016/j.indcrop.2003.09.001

50. Pérez-Jiménez J, Neveu V, Vos F, Scalbert A (2010) Identification of the 100 richest dietary sources of polyphenols: an application of the Phenol-Explorer database. Eur J Clin Nutr 64:112-120. https://doi.org/10.1038/ejen.2010.221

51. Saravanan K, Aradhya SM (2011) Polyphenols of pseudostem of different banana cultivars and their antioxidant activities. J Agric Food Chem 59:3613-3623. https://doi.org/10.1021/jf103835z

52. Aboul-Enein AM, Salama ZA, Gaafar AA et al (2016) Identification of phenolic compounds from banana peel (Musa paradaisica L.) as antioxidant and antimicrobial agents. J Chem Pharm Res $8: 46-55$

53. Sidhu JS, Zafar TA (2018) Bioactive compounds in banana fruits and their health benefits. Food Qual Saf 2:183-188
54. Fernández-Agulló A, Freire MS, Ramírez-López C et al (2021) Valorization of residual walnut biomass from forest management and wood processing for the production of bioactive compounds. Biomass Conv Bioref 11:609-618. https://doi.org/10.1007/ s13399-019-00598-9

55. Do QD, Angkawijaya AE, Tran-Nguyen PL et al (2014) Effect of extraction solvent on total phenol content, total flavonoid content, and antioxidant activity of Limnophila aromatica. J Food Drug Anal 22:296-302. https://doi.org/10.1016/j.jfda.2013.11.001

56. Prior RL, Wu X, Schaich K (2005) Standardized methods for the determination of antioxidant capacity and phenolics in foods and dietary supplements. J Agric Food Chem 53:4290-4302

57. Jokic S, Velic D, Bilic M et al (2010) Modelling of the process of solid-liquid extraction of total polyphenols from soybeans. Czech J Food Sci 28:206-212. https://doi.org/10.17221/200/2009-cjfs

58. Huang W, Xue A, Niu H et al (2009) Optimised ultrasonic-assisted extraction of flavonoids from Folium eucommiae and evaluation of antioxidant activity in multi-test systems in vitro. Food Chem 114:1147-1154. https://doi.org/10.1016/j.foodchem.2008.10.079

59. González-Montelongo R, Gloria Lobo M, González M (2010) Antioxidant activity in banana peel extracts: testing extraction conditions and related bioactive compounds. Food Chem 119:1030-1039. https://doi.org/10.1016/j.foodchem.2009.08.012

60. Babbar N, Oberoi HS, Sandhu SK (2015) Therapeutic and nutraceutical potential of bioactive compounds extracted from fruit residues. Crit Rev Food Sci Nutr 55:319-337. https://doi.org/10. 1080/10408398.2011.653734

61. Karabegović I, Mančić D, Nikolić N et al (2018) Total polyphenols from Solanum retroflexum Dun. fruit: extraction and optimization by response surface methodology. J Food Meas Charact 12:1772-1778. https://doi.org/10.1007/s11694-018-9792-6

Publisher's note Springer Nature remains neutral with regard to jurisdictional claims in published maps and institutional affiliations. 